\title{
A modified Gompertz model to predict microbial inactivation under time-varying temperature conditions
}

\author{
Maria M. Gil, Teresa R.S. Brandão, Cristina L.M. Silva* \\ Universidade Católica Portuguesa, Escola Superior de Biotecnologia, Rua Dr. António Bernardino de Almeida, 4200-072 Porto, Portugal
}

Keywords: Predictive microbiology; Gompertz model; Inactivation kinetics; Time-varying temperature

\begin{abstract}
Development of effective heat treatments is crucial to achieve food products' safety, and predictive microbiology is an excellent tool to design adequate processing conditions.

This work focuses on the application of a modified Gompertz model to describe the inactivation behaviour under time-varying temperature conditions at the surface of a food product. Kinetic studies were carried out assuming two different heating regimes, typically used in surface pasteurisation treatments, and compared with isothermal conditions. Parameters were estimated on the basis of generated pseudo-experimental data. It was concluded that the heating period greatly affects microbial inactivation and parameter estimation. If a slow heating treatment is used, the process time should be extended to achieve a given microbial load when compared to a fast heating process. This is explained by the fact that, in the slow heating rate process the temperature was below the lowest temperature for inactivation for a much longer time, in comparison with the fast heating regime.
\end{abstract}

\section{Introduction}

The bacterial spoilage of foods and the survival of pathogens are of major importance to the food process industries, because it directly affects the consumer's health and safety. As the critical boundary for contamination is the exposed surface, heat treatments at food surface can be an effective mean of controlling pathogens. This makes effective surface pasteurisation systems critical to produce safe products (Kozempel, Goldberg, Radewonuk, \& Scullen, 2000). Consequently, thermal decontamination must be designed to provide an adequate margin of safety against food-borne pathogens. However, it is difficult to determine the exact amount of microbial inactivation when these treatments are applied (James \& James, 1997). Kinetic models are

\footnotetext{
* Corresponding author. Tel.: +351 22 5580058; fax: +351 22 5090351.

E-mail address: crislui@esb.ucp.pt (C.L.M. Silva).
}

mathematical expressions that relate a particular measured response with time, under specific environmental conditions. In predictive microbiology (Roberts \& Jarvis, 1983), these models should be developed to predict the behaviour of pathogens or spoiling microorganisms populations under stress factors (e.g., high temperature, particular ranges of $\mathrm{pH}$ and $\mathrm{a}_{w}$ ), precisely and accurately, being of main importance for the food industry in the development of reliable surface pasteurisation systems. Nevertheless, modelling microbial kinetics, that lead to reliable predictions of safety and shelf life of foods, is only recently used (MacDonald \& Sun, 1999). An overview of the models used in literature to describe microbial inactivation was done by Xiong, Xie, Edmondson, Linton, and Sheard (1999). Those models describe linear and non-linear curves, with lag and/or tailing phases. Among non-linear models, the Gompertz equation and its modified forms have been successfully applied to describe inactivation of Listeria monocytogenes at isothermal conditions (Bhaduri et 


\begin{tabular}{|c|c|c|c|}
\hline \multicolumn{4}{|c|}{ Nomenclature } \\
\hline$a$ & parameter of the relationship of $L$ with $T$ (s) & $T$ & temperature $(\mathrm{K})$ \\
\hline$b$ & $\begin{array}{l}\text { parameter of the relationship of } L \text { with } T \\
\left(\mathrm{~K}^{-1}\right)\end{array}$ & $T_{\text {ref }}$ & reference temperature $(\mathrm{K})$ \\
\hline$c$ & $\begin{array}{l}\text { parameter of the relationship of } k \text { with } T \\
\left(\mathrm{~s}^{-1} \mathrm{~K}^{-2}\right)\end{array}$ & \multicolumn{2}{|c|}{ Greek symbols } \\
\hline$d$ & parameter of the relationship of $k$ with $T(\mathrm{~K})$ & & \\
\hline$e$ & level of the pseudo-experimental error & \multicolumn{2}{|c|}{ Subscripts } \\
\hline$N$ & microbial cell density $\left(\mathrm{cfu} \mathrm{g}^{-1}\right)$ & $\exp$ & pseudo-experimental value \\
\hline$N_{0}$ & initial microbial cell density $\left(\mathrm{cfu} \mathrm{g}^{-1}\right)$ & $\operatorname{sim}$ & simulated value \\
\hline$N_{f}$ & residual microbial cell density $\left(\mathrm{cfu} \mathrm{g}^{-1}\right.$ ) & & \\
\hline$K$ & maximum inactivation rate constant $\left(\mathrm{s}^{-1}\right)$ & \multicolumn{2}{|c|}{ Abbreviations } \\
\hline$L$ & time parameter or shoulder $(\mathrm{s})$ & $\mathrm{cfu}$ & colony forming unit \\
\hline$R^{2}$ & coefficient of determination & MSE & mean sum of squares of the residuals \\
\hline$t$ & time $(s)$ & SHW & standardised half width $(\%)$ \\
\hline$t^{\prime}$ & dummy variable & & \\
\hline
\end{tabular}

al., 1991; Linton, Carter, Pierson, \& Hackney, 1995; Linton, Carter, Pierson, Hackney, \& Eifert, 1996; Xiong et al., 1999).

Actually, the majority of predictive approaches are based on un-realistic isothermal conditions (Peleg, Penchina, \& Cole, 2001; Reichart, 1994). Yet, it is well known that temperature may vary extensively throughout the complete process. The kinetic parameters, estimated under time-varying temperature conditions, may differ from the ones predicted at constant temperatures. Using the later ones, in situations in which the temperature varies with the time, may affect the predictive ability of the model. This can be particularly important when the safety of a product is the final goal. In order to appropriately describe the real microbial behaviour, surface thermal models should be designed to include the variations of temperature along the total process time. This could be enhanced by the numerical integration approach. A non-isothermal kinetic model was developed by Van Impe, Nicolaï, Martens, De Baerdemaeker, and Vandewalle (1992) by differentiating a modified Gompertz equation with respect to time, in combination with an Arrhenius-type equation to describe the microbial load as a function of both time and temperature. Geeraerd, Herremans, and Van Impe (2000) also referred the need of applying differential equations, as well as the design requirements, and compared the most relevant models used to describe the inactivation microorganisms kinetics under time-varying environmental conditions.

The objective of this work was to develop a model to predict the survival of microorganisms on the surface of a food product, able to deal with typical temperature profiles during air surface decontamination treatments. The Gompertz model was applied by differentiating the isothermal model with respect to time. The regres- sion procedure was tested using pseudo-experimental data generated considering time-varying temperature conditions. The influence of the heating period on microbial inactivation was also studied.

\section{Model description}

The mathematical model used to describe inactivation of microorganisms was based on modifications of the Gompertz equation (Zwietering, Jongenburger, Rombouts, \& Van't Riet, 1990). The inactivation model considered, valid for isothermal conditions, is:

$$
\begin{aligned}
\log N= & \log N_{0}-\log \left(\frac{N_{0}}{N_{f}}\right) \\
& \times \exp \left(-\exp \left(\frac{k \exp (1)}{\log \left(\frac{N_{0}}{N_{f}}\right)}(L-t)+1\right)\right)
\end{aligned}
$$

Herein, $N$ represents the microbial cell density at a certain process time $(t), L$ is the time parameter (or shoulder) and $\mathrm{k}$ the maximum inactivation rate constant. $N_{0}$ and $N_{f}$ are the initial and residual microbial cell density, respectively.

By differentiating Eq. (1) with respect to time, one can generally obtain an expression applicable for timevarying temperature conditions:

$\log N$

$$
\begin{gathered}
=\log N_{0}-\int_{0}^{t}\left[k \exp (1) \exp \left(\frac{k \exp (1)}{\log \left(\frac{N_{0}}{N_{f}}\right)}\left(L-t^{\prime}\right)+1\right)\right. \\
\left.\quad \times \exp \left(-\exp \left(\frac{k \exp (1)}{\log \left(\frac{N_{0}}{N_{f}}\right)}\left(L-t^{\prime}\right)+1\right)\right)\right] \mathrm{d} t^{\prime}
\end{gathered}
$$


The model parameters $(k$ and $L)$ are temperature dependent. In processes in which the temperature varies with time, those parameters are obviously time-temperature relying. An Arrhenius type-equation was used to describe the temperature effect on $L$, as follows:

$L=a \exp \left(b\left(\frac{1}{T}-\frac{1}{T_{\text {ref }}}\right)\right)$

where $a$ and $b$ are parameters and $T_{\text {ref }}$ is a fixed reference temperature.

In relation to the rate constant, the expression used is (Ratkowsky, Olley, McMeekin, \& Ball, 1982):

$k=c(T-d)^{2}$

$c$ and $d$ being parameters.

If expressions 3 and 4 are included in Eq. (2), one obtains a mathematical model that describes the microbial content along time and temperature. Three main assumptions were in the backstage of the model development, as highlighted in Valdramidis et al. (2005): (i) no microbial growth occurs during the come-up time of the non-isothermal heat treatment; (ii) there is a limit of temperature below which no inactivation is observed (i.e., $k$ is set to zero for temperatures lower than this limit), and (iii) the temperature history has not a significant effect on the microbial heat resistance, thus meaning that the use of the actual temperature in expressions 3 and 4 is adequate.

\section{Methodology}

\section{Pseudo-experimental data generation}

Microbial inactivation data were computer-generated using the modified Gompertz model (merging Eqs. (2)(4)). Assuming given parameters, simulated values of microbial load were calculated, $\left(\log N_{\text {sim }}\right)$. The values of the parameters used in the simulation $\left(\log N_{0}=7\right.$; $\log N_{f}=1.5 ; \quad a=57.34 \mathrm{~s} ; \quad b=5.559 \times 10^{4} \mathrm{~K}^{-1} ; \quad c=$ $\left.5.806 \times 10^{-4} \mathrm{~s}^{-1} \mathrm{~K}^{-2} ; d=326.2 \mathrm{~K}\right)$ were the ones estimated by Gil, Brandão, and Silva (2003) on the basis of experimental inactivation data of $L$. monocytogenes Scott A published by Casadei, Esteves de Matos, Harrison, and Gaze (1998). Five isothermal experiences were considered in the range $52-68^{\circ} \mathrm{C}(52,56,60,64$, and $68^{\circ} \mathrm{C}$ ). The lower limit of the temperature range, $52^{\circ} \mathrm{C}$, was assumed to be the starting temperature for inactivation.

The reference temperature in Eq. (3) was assumed to be $60^{\circ} \mathrm{C}$ (i.e., middle value of the range $52-68^{\circ} \mathrm{C}$ ), as parameter estimation is improved (Cohen, Birk, Mannheim, \& Saguy, 1994).

As suggested by Haralampu, Saguy, and Karel (1985), pseudo-experimental data $\left[(\log N)_{\exp }\right]$ can be ob- tained by adding an error term [c] to simulated values [( $\left.\log N)_{\text {sim }}\right]$, as follows:

$$
\begin{aligned}
& (\log N)_{\exp _{i}}=(\log N)_{\operatorname{sim}_{i}}+\varepsilon_{i} \\
& i=1,2 \ldots, n \text { number of points }
\end{aligned}
$$

The error term $\varepsilon$ was randomly selected from a normal population, $\varepsilon \approx N\left(0,\left((\log N)_{\operatorname{sim}_{i}} e\right)^{2}\right)$, using a Gaussian random number generator (Microsoft Excel $^{\circledR}, 2000$ was used). The level of the pseudo-experimental error was chosen to be $10 \%(e=0.10)$.

Twenty data points, equally spaced in the time scale, were generated and considered as experimental.

\section{Temperature histories}

The temperature histories used were measured at the surface of solid foods in a decontamination rig (designed by FRPERC, University of Bristol, in the framework of the European project BUGDEATH QLRT-200101415). Two different heating processes were considered: (i) one in which the heater was controlled so that the surface of the product follows a rapid ramp from 5 to $60{ }^{\circ} \mathrm{C}$ in $30 \mathrm{~s}$, and then holds the surface at $60^{\circ} \mathrm{C}$ until $400 \mathrm{~s}$; (ii) another one in which the temperature of the product follows a slow heating rate from 5 to $60^{\circ} \mathrm{C}$ in $180 \mathrm{~s}$, and then holds the surface at around $60{ }^{\circ} \mathrm{C}$ for the remaining process time. A third process was considered where ideally the temperature was maintained constant $\left(\right.$ at $60{ }^{\circ} \mathrm{C}$ ) during the whole process.

The temperature histories of the heating regimes considered are presented in Fig. 1.

Regression analysis procedure

Estimates of the kinetic parameters were obtained by non-linear regression analysis, fitting Eq. (2) to the

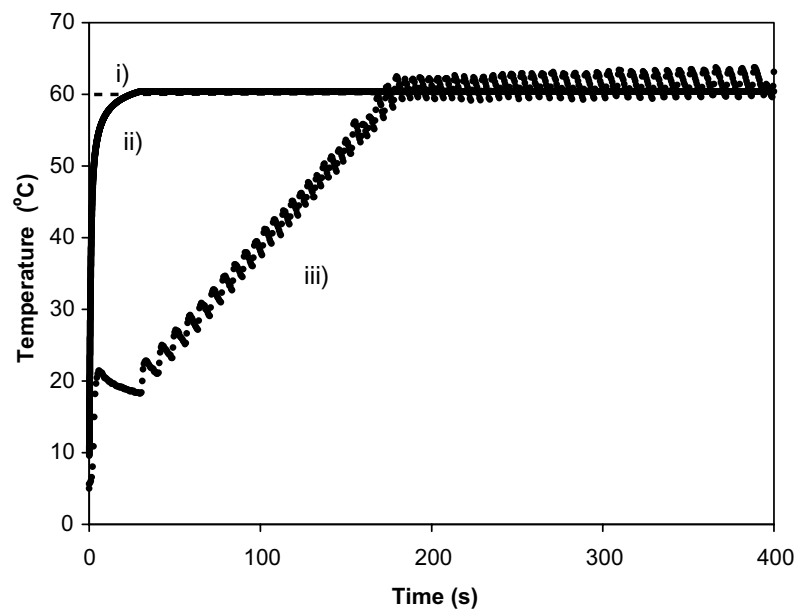

Fig. 1. Temperature histories at the food surface. (i) Isothermal process; (ii) fast heating; and (iii) slow heating. 
non-isothermal pseudo-experimental data. The minimal temperature for inactivation was assumed to be $52{ }^{\circ} \mathrm{C}$ and $T_{\text {ref }}$, in the Arrhenius-dependence of $L$ with temperature, was considered equal to $60^{\circ} \mathrm{C}$ (the same values used in pseudo-experimental data generation).

The simplex algorithm (Nelder \& Mead, 1965) was used to minimise the sum of the squares of the residuals. The quality of the regression was evaluated by the coefficient of determination $\left(R^{2}\right)$, randomness and normality of the residuals, and the value of the mean sum of squares of the residuals (MSE).

Precision of the parameter estimates was evaluated by the standardised half width at $95 \%$, SHW (i.e., halved confidence interval at $95 \%$, divided by the estimate $\equiv \frac{\text { confidence interval }{ }_{95 \%}}{2} \times \frac{1}{\text { estimate }} \times 100$ ).

All regression analysis procedures and calculations were performed in programs specially written in FORTRAN 77 language (Fortran 5.1, Microsoft Corporation $\left.^{\circledR}, 1990\right)$.

\section{Results and discussion}

The objective of basing these studies on pseudo-experimental data had the main purpose of testing non-linear regression analysis procedures using the Gompertz model modified for describing inactivation under time-varying temperature conditions. This procedure avoids experimental effort in a stage in which the main purpose is to test all statistical procedures. Important conclusions related to experimental design may be extracted by generating pseudo-experimental data, that might also be relevant in performing profitable real experiments. Nevertheless, experimental data sets are needed to validate the underlying assumptions and conclusions. This type of approach was already applied in studies of regression analysis procedures aiming at kinetic parameters estimation in the context of degradation of food constituents or quality factors (Haralampu et al., 1985; Nunes, Rhim, \& Swartzel, 1991) and in mass transfer studies (Azevedo, Oliveira, \& Drumond, 1998; Brandão \& Oliveira, 1997).

Fits of the modified Gompertz model to pseudoexperimental data are presented in Fig. 2, for the heat treatments considered. For the sake of comparison, in the same figure are included the simulated values. Concerning the isothermal process at $60^{\circ} \mathrm{C}$ (Fig. 2a), only simulated data are presented, because the purpose was not to test the regression analysis procedure in such circumstances, but to consider it as the comparative term to data simulated at time-varying temperature treatments in which $60^{\circ} \mathrm{C}$ was the highest temperature achieved.

Comparing temperature histories at product surface and corresponding Listeria inactivation simulated curves (Figs. 1 and 2), one can easily observe that the
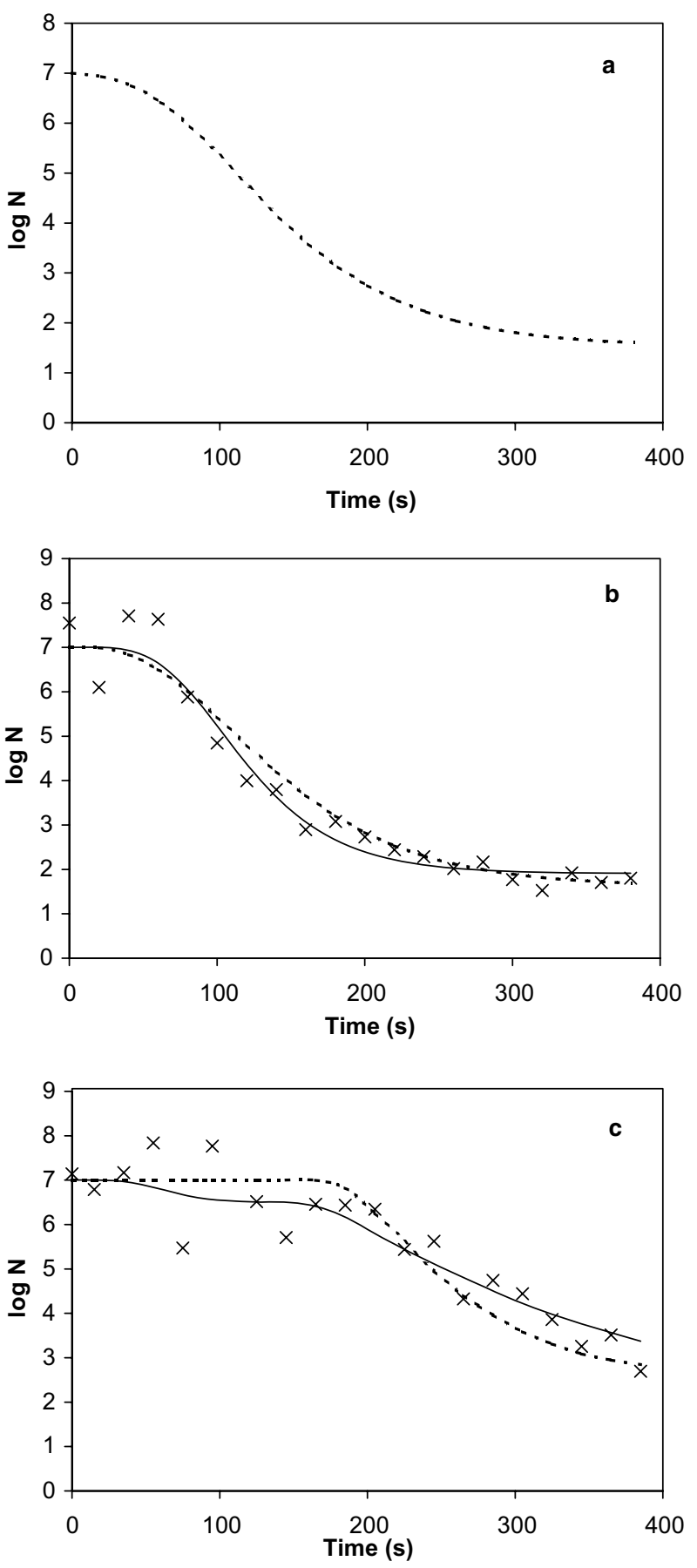

Fig. 2. Microbial inactivation during heat treatments: (a) Isothermal process $\left(T=60^{\circ} \mathrm{C}\right)$; (b) fast heating process; and (c) slow heating process. $(\times)$ Pseudo-experimental data, (--) simulated values, and $(-)$ estimated values.

effect of the heating period is notorious. Although the total process time was the same in the three treatments considered (approximately $400 \mathrm{~s}$ ), it was found that if a slow heating rate precedes the holding period, the total process time should be extended to achieve the same residual microbial content (which could be a target safety value), as observed for the fast heating process 
Table 1

Parameter estimates of the modified Gompertz model and relevant regression analysis results

\begin{tabular}{|c|c|c|c|c|c|c|c|c|}
\hline \multirow[t]{2}{*}{ Heating regime } & \multicolumn{5}{|c|}{ Parameter estimates } & \multicolumn{3}{|c|}{ Regression analysis } \\
\hline & $\overline{\log N_{f}}$ & $a(\mathrm{~s})$ & $b\left(\mathrm{~K}^{-1}\right)$ & $c\left(\mathrm{~s}^{-1} \mathrm{~K}^{-2}\right)$ & $d(\mathrm{~K})$ & $\overline{R^{2}}$ & MSE & Randomness of the residuals \\
\hline$\overline{\text { Fast }}$ & 1.890 & $6.649 \times 10^{1}$ & $2.827 \times 10^{4}$ & $6.960 \times 10^{-4}$ & $3.416 \times 10^{2}$ & 0.953 & 0.7843 & Yes \\
\hline Slow & $5.851 \times 10^{-8}$ & $4.125 \times 10^{1}$ & $1.637 \times 10^{3}$ & $7.231 \times 10^{-5}$ & $3.187 \times 10^{2}$ & 0.847 & 2.6540 & Yes \\
\hline
\end{tabular}

Table 2

Precision of the estimates evaluated by the standardised half width at $95 \%$

\begin{tabular}{|c|c|c|c|c|c|}
\hline \multirow[t]{2}{*}{ Heating regime } & \multicolumn{5}{|c|}{ Standardised half width at $95 \%$ of the parameters } \\
\hline & $\log N_{f}$ & $a$ & $b$ & $c$ & $d$ \\
\hline Fast & $1.010 \times 10^{-3}$ & 3.46 & 172.4 & $2.095 \times 10^{-5}$ & $3.198 \times 10^{-6}$ \\
\hline Slow & $6.354 \times 10^{-8}$ & 47.08 & 227.0 & $8.533 \times 10^{-1}$ & $5.885 \times 10^{-2}$ \\
\hline
\end{tabular}

(Fig. $2 b$ and c). At the end of the total process time, these treatments differ in a 2-log bacterial reduction.

As the initial increasing rate of the temperature of the fast heating process is considerable high, the process can be compared to the one where the temperature is hold at $60{ }^{\circ} \mathrm{C}$ (isothermal). Comparable simulated inactivation data were obtained for both situations (Fig. 2a and b).

Estimates of the parameters and results of the regression analysis of non-isothermal data are shown in Table 1. The analysis of the residuals showed that randomness was verified, as well as normality behaviour. A runs test (Walpole \& Meyers, 1993) was carried out for detecting departures in randomness, and results proved that residuals were random in both cases.

Although a bias was not identified in the results of the slow heating process, the coefficient of determination was lower (equal to 0.847 , while the one for the fast heating was 0.953 ), which means that only $84.7 \%$ of the total variation was explained by the model. For this situation, a higher value of the residuals (evaluated by the mean sum of squares) was obtained. This may be an indication of lack of fit, that may be explained by extension of the initial lag phase (directly related with the lowest temperature for inactivation assumed) when compared to kinetic inactivation data. In such situation, better results might be obtained if another experimental design was chosen. An alternative could be a sample pattern, such that fewer samples were collected at the beginning of the process, and more samples were taken in the period of maximum inactivation rate.

Concerning parameters' precision, evaluated by SHW of the estimates at $95 \%$ (Table 2), worse results were obtained for the slow heating process (i.e., higher SHW values). An exception was observed for $\log N_{f}$ that was more precise. Curiously, if accuracy is analysed (accuracy stands for deviation to the 'real' value), $\log N_{f}$ deviates considerable to the value assumed in simulation $\left(\log N_{f}=1.5\right)$. This means that, besides precision of parameters is attained, accuracy is strongly sacrificed, which directly affects the predictive ability of the model. This fact also reinforces the need of the careful selection of the experimental data collection in non-isothermal processes, and the extent of time required to reach equilibrium. Brandão and Oliveira (1997) arrived at interesting conclusions concerning the influence of temperature increase rate on the accuracy of diffusion parameters of food processes estimated at non-isothermal conditions.

The high number of parameters of the model (five) may difficult the convergence procedure, as the estimates were highly correlated. Nevertheless, non-linear regression procedures were successfully applied.

\section{Conclusions}

Modifications of the Gompertz equation were proposed to describe inactivation data of microorganisms. The model proved to have the ability to deal with timevarying temperature conditions, and required non-linear regression schemes and analyses were tested on the basis of pseudo-experimental generated data.

It may be concluded that the heating period greatly affects bacterial inactivation. One should be aware that if a slow heating process is chosen, the time of the process should be extended to achieve a specified target microbial load when compared to a fast heating process. This is directly related to the lowest temperature for inactivation assumed, which emphasizes the need of an accurate experimental determination of the value.

\section{Acknowledgement}

This work was supported by the European Commission under the Framework 5, Quality of Life and Management of Living Resources Programme, as part of the project BUGDEATH (QLRT-2001-01415). 


\section{References}

Azevedo, I. C. A., Oliveira, F. A. R., \& Drumond, M. C. (1998). A study on the accuracy and precision of external mass transfer and diffusion coefficients jointly estimated from pseudo-experimental simulated data. Mathematics and Computers in Simulation, 48, $11-22$.

Bhaduri, S., Smith, P. W., Palumbo, S. A., Turmer-Jones, C. O., Smith, J. L., Marmer, B. S., et al. (1991). Thermal destruction of L. monocytogenes in liver sausage slurry. Food Microbiology, 8, 75-78.

Brandão, T. R. S., \& Oliveira, F. A. R. (1997). The influence of the temperature increase rate on the accuracy of diffusion parameters estimated under non-isothermal conditions. International Journal of Food Science and Technology, 32, 63-72.

Casadei, M. A., Esteves de Matos, R., Harrison, S. T., \& Gaze, J. E. (1998). Heat resistance of Listeria monocytogenes in dairy products as affected by the growth medium. Journal of Applied Microbiology, 84, 234-239.

Cohen, E., Birk, Y., Mannheim, C. H., \& Saguy, I. S. (1994). Kinetic parameter estimation for quality change during continuous thermal processing of grapefruit juice. Journal of Food Science, 59, 155-158.

Geeraerd, A. H., Herremans, C. H., \& Van Impe, J. F. (2000). Structural model requirements to describe microbial inactivation during a mild heat treatment. International Journal of Food Microbiology, 59, 185-209.

Gil, M. M., Brandão, T. R. S., \& Silva, C. L. M. (2003). Modelling inactivation kinetics of Listeria monocytogenes in a dairy product. Poster presented in: IUFoST-12th World Food Science and Technology Congress, Chicago, USA.

Haralampu, S. G., Saguy, I., \& Karel, M. (1985). Estimation of Arrhenius model parameters using three least squares methods. Journal of Food Process and Preservation, 9, 129-135.

James, C., \& James, S. (1997). Food process engineering. UK: MAFF (p. 140).

Kozempel, M., Goldberg, N., Radewonuk, E. R., \& Scullen, O. J. (2000). Commercial testing and optimization studies of the surface pasteurization process of chicken. Journal of Food Process Engineering, 23, 387-402.

Linton, R. H., Carter, W. H., Pierson, M. D., \& Hackney, C. R. (1995). Use of a modified Gompertz equation to model nonlinear survival curves for Listeria monocytogenes Scott A. Journal of Food Protection, 58, 946-954.

Linton, R. H., Carter, W. H., Pierson, M. D., Hackney, C. R., \& Eifert, J. D. (1996). Use of a modified Gompertz equation to predict the effects of temperature, $\mathrm{pH}$, and $\mathrm{NaCl}$ on the inactivation of Listeria monocytogenes Scott A heated in infant formula. Journal of Food Protection, 59, 16-23.

MacDonald, K., \& Sun, D. W. (1999). Predictive food microbiology for the meat industry: a review. International Journal of Food Microbiology, 52, 1-27.

Nelder, J. A., \& Mead, R. (1965). A simplex method for function minimization. The Computer Journal, 7(4), 308-313.

Nunes, R. V., Rhim, J. W., \& Swartzel, K. R. (1991). Kinetic parameter evaluation with linearly increasing temperature profiles: Integral methods. Journal of Food Science, 56(5), 1433-1437.

Peleg, M., Penchina, C. M., \& Cole, M. B. (2001). Estimation of the survival curve of Listeria monocytogenes during non-isothermal heat treatments. International Journal of Food Microbiology, 34, 383-388.

Ratkowsky, D. A., Olley, J., McMeekin, T. A., \& Ball, A. (1982), Relationship between temperature and growth rate of bacterial cultures. Journal of Bacteriology, 149, 1-5.

Reichart, O. (1994). Modelling the destruction of Escherichia coli on the base of reaction kinetics. International Journal of Food Microbiology, 23, 449-465.

Roberts, T. A., \& Jarvis, B. (1983). Predictive modelling of safety with particular reference to Clostridium botulinum. In T. A. Roberts \& F. A. Skinner (Eds.), Food microbiology, advances and prospects (pp. 85-95). New York: Academic Press.

Valdramidis, V. P., Belaubre, N., Zuniga, R., Foster, A. M., Havet, M., Geeraerd, A. H., et al. (2005). Development of predictive modelling approaches for surface temperature and associated microbiological inactivation during hot air decontamination. International Journal of Food Microbiology, 100(1-3), 261-274.

Van Impe, J. F., Nicolaï, B. M., Martens, T., De Baerdemaeker, J., \& Vandewalle, J. (1992). Dynamic mathematical model to predict microbial growth and inactivation during food processing. Applied and Environmental Microbiology, 58(9), 2901-2909.

Walpole, R. E., \& Meyers, R. H. (1993). Probability and statistics for engineers and scientists (5th ed.). New York: Macmillan Publishing Company.

Xiong, R., Xie, G., Edmondson, A. S., Linton, R. H., \& Sheard, M. A. (1999). Comparison of the Baranyi model with the Gompertz equation for modelling thermal inactivation of Listeria monocytogenes Scott A. Food Microbiology, 16, 269-279.

Zwietering, M. H., Jongenburger, I., Rombouts, F. M., \& Van't Riet, K. (1990). Modelling of the bacterial growth curve. Applied and Environmental Microbiology, 56(6), 1875-1881. 